\title{
Muscarinic Tone Sustains Impulse Flow in the Septohippocampal GABA But Not Cholinergic Pathway: Implications for Learning and Memory
}

\author{
Meenakshi Alreja, ${ }^{1,2}$ Min Wu, ${ }^{1}$ Weimin Liu, ${ }^{1}$ Joshua B. Atkins, ${ }^{1}$ Csaba Leranth, ${ }^{1,3}$ and Marya Shanabrough ${ }^{3}$ \\ Departments of ${ }^{1}$ Psychiatry, ${ }^{2}$ Neurobiology, and ${ }^{3}$ Obstetrics and Gynecology, Yale University School of Medicine and the \\ Ribicoff Research Facilities, Connecticut Mental Health Center, New Haven, Connecticut 06508
}

\begin{abstract}
Systemic infusions of the muscarinic cholinergic receptor antagonists atropine and scopolamine (atr/scop) produce an amnesic syndrome in humans, subhuman primates, and rodents. In humans, this syndrome may resemble early symptoms of Alzheimer's disease. Behavioral studies in rats have demonstrated that the medial septum/diagonal band of Broca (MSDB), which sends cholinergic and GABAergic projections to the hippocampus, is a critical locus in mediating the amnesic effects of atr/scop. The amnesic effects of atr/scop in the MSDB have been presumed but not proven to be caused by a decrease in hippocampal acetylcholine (ACh) release after blockade of a muscarinic tone in the MSDB. Using electrophysiological recordings and fluorescent-labeling techniques to identify living septohippocampal neurons in rat brain slices, we now report that, contrary to current belief, a blockade of the muscarinic tone in the MSDB does not decrease impulse flow in the septohippocampal cholinergic pathway; instead, it decreases impulse flow in the septohippocampal GABAergic pathway via $M_{3}$ muscarinic
\end{abstract}

receptors. We also report that the muscarinic tone in the MSDB is maintained by ACh that is released locally, presumably via axon collaterals of septohippocampal cholinergic neurons. As such, cognitive deficits that occur in various neurodegenerative disorders that are associated with a loss or atrophy of septohippocampal cholinergic neurons cannot be attributed solely to a decrease in hippocampal acetylcholine release. An additional, possibly more important mechanism may be the concomitant decrease in septohippocampal GABA release and a subsequent disruption in disinhibitory mechanisms in the hippocampus. Restoration of impulse flow in the septohippocampal GABA pathway, possibly via $\mathrm{M}_{3}$ receptor agonists, may, therefore, be critical for successful treatment of cognitive deficits associated with neurodegenerative disorders such as Alzheimer's and Parkinson's disease.

Key words: $\theta$ rhythm; p75 receptor; neurotrophin; acetylcholine; cognition; neurodegeneration
The importance of cholinergic mechanisms for the maintenance of cognitive functioning is well established, and acetylcholinesterase inhibitors, which increase synaptic acetylcholine (ACh) levels, are the most extensively used therapy for Alzheimer's disease. In contrast, treatments that oppose cholinergic tone, such as the muscarinic receptor antagonists atropine and scopolamine (atr/ scop), produce an amnesic syndrome in rats (Deutsch and Rocklin, 1967), monkeys (Rupniak et al., 1989), and humans (Bartus, 1978; Rusted and Warburton, 1988). In humans, this syndrome is reminiscent of the dementias associated with Alzheimer's disease and the alcoholic Korsakoff syndrome (Kopelman and Corn, 1988; Izquierdo, 1989) in which a loss in brain cholinergic neurons occurs. In these and other neurodegenerative disorders such as Parkinson's disease, Lewy body dementia, and Down syndrome, the loss or atrophy of cholinergic neurons has been especially noted in the nucleus basalis and in the medial septum/diagonal band of Broca (MSDB) (Whitehouse et al., 1982; Mufson et al., 1989; Arendt et al., 1995).

The MSDB, which is the primary source of ACh for the hippocampus, is also a critical locus for the amnesic effects of atr/scop (Givens and Olton, 1994). Thus, infusions of muscarinic agonists into the MSDB alleviate the learning and memory deficits induced by systemic atr/scop, whereas intraseptal infusions of atr/scop strongly mimic the impairments induced by systemic antagonists

Received June 20, 2000; revised Aug. 9, 2000; accepted Aug. 16, 2000.

This work was supported by the National Alliance for Research on Schizophrenia and Depression and National Institutes of Health Grants DA 09797 and DA 08227 to M.A. and National Institutes of Health Grant NS 26068 to C.L. We thank Nancy Margiotta for technical help and Leslie Rosello for help in manuscript preparation.

Correspondence should be addressed to Dr. Meenakshi Alreja, Department of Psychiatry, Connecticut Mental Health Center 335A, Yale University School of Medicine, 34 Park Street, New Haven, CT 06508. E-mail: Meenakshi.Alreja@ yale.edu.

Copyright (C) 2000 Society for Neuroscience $\quad 0270-6474 / 00 / 208103-08 \$ 15.00 / 0$
(Givens and Olton, 1995) and also block the hippocampal $\theta$ rhythm (see Stewart and Fox, 1990; Givens and Olton, 1994).

Despite its importance, the cellular mechanism(s) underlying the muscarinic tone in the MSDB has never been elucidated. It has, however, been presumed that muscarinic antagonists in the MSDB act by decreasing an excitatory muscarinic tone on septohippocampal cholinergic neurons that would subsequently reduce hippocampal ACh release and, as a consequence, impair performance in learning and memory tasks (Givens and Olton, 1994; Givens and Sarter, 1997). Our recent findings, however, provide strong evidence that septohippocampal cholinergic neurons are actually never excited by muscarinic agonists but are instead inhibited by them (Wu et al., 2000). Theoretically, therefore, if cholinergic neurons were indeed under a muscarinic tone, administration of muscarinic antagonists would increase and not decrease impulse flow in the septohippocampal cholinergic pathway. The increased hippocampal ACh release should then facilitate learning and memory processes. How then do muscarinic receptor antagonists produce amnesia?

A second, very important issue relates to the source of ACh that provides a muscarinic tone in the MSDB. Theoretically, the muscarinic tone in the MSDB could be caused by ACh released via the extrinsic brainstem cholinergic afferents to the MSDB (Woolf and Butcher, 1986) and/or caused by ACh released from within the nucleus via collaterals of septohippocampal cholinergic neurons (Bialowas and Frotscher, 1987; Leranth and Frotscher, 1989). If the muscarinic tone were to be dependent, even in part, on the septohippocampal cholinergic neurons, then it would be compromised in the above-mentioned neurodegenerative disorders in which a loss or atrophy of septohippocampal but not brainstem cholinergic neurons occurs. Thus, the question of the source of the muscarinic tone in the MSDB is of great therapeutic significance. In our previous in vitro studies, we observed that identified septohippocampal cholinergic neurons within the MSDB are spontaneously 
firing and thus capable of tonically releasing ACh locally via axon collaterals (Wu et al., 2000). We therefore hypothesized that the cholinergic tone in the MSDB, which is critical to learning and memory in vivo, may, at least in part, be caused by $\mathrm{ACh}$ that is released locally by the spontaneously firing septohippocampal cholinergic neurons. The present study was therefore designed to determine the cellular mechanisms underlying the muscarinic tone in the MSDB.

\section{MATERIALS AND METHODS}

Slice preparation for electrophysiological recordings. Brain slices containing the MSDB were prepared from young adult male Sprague Dawley albino rats (2-4 weeks old) by the use of methods detailed previously (Alreja and Liu, 1996). Briefly, rats were anesthetized with chloral hydrate $(400 \mathrm{mg} / \mathrm{kg}$, i.p.) and killed by decapitation. The artificial CSF (ACSF), pH 7.35-7.38, equilibrated with $95 \% \mathrm{O}_{2} / 5 \% \mathrm{CO}_{2}$, contained (in $\mathrm{mM}$ ): $\mathrm{NaCl}, 126 ; \mathrm{KCl}, 3$; $\mathrm{NaH}_{2} \mathrm{PO}_{4}, 1.25 ;$ D-glucose, $10 ; \mathrm{NaHCO}_{3}, 25 ; \mathrm{CaCl}_{2}, 2$; and $\mathrm{MgSO}_{4}, 2$. After decapitation, the brain was removed and placed in a Petri dish containing ACSF and trimmed to yield a small block containing the MSDB. Coronal slices of $\sim 300 \mu \mathrm{m}$ thickness containing the MSDB were cut with a vibrating-knife microtome (Frederick Haer, Brunswick, ME) and transferred to a Plexiglas recording chamber (1.5 $\mathrm{ml}$ volume) on the fixed stage of an Olympus BX50WI scope. Sagittal slices were used for antidromic activation studies (see below). The slice was kept in place with a grid and maintained at $33 \pm 0.5^{\circ} \mathrm{C}$. One to $2 \mathrm{hr}$ later the slice was used for recording. The chamber was continuously perfused with normal ACSF at a rate of $1-2 \mathrm{ml} / \mathrm{min}$.

Labeling of septohippocampal cholinergic neurons using indocarbocyanine-192IgG. Young adult male Sprague Dawley albino rats $(14-21 \mathrm{~d}$ old) were anesthetized with the following cocktail: ketamine at $75 \mathrm{mg} / \mathrm{kg}$, Xylazine at $4 \mathrm{mg} / \mathrm{kg}$, and acepromazine at $0.075 \mathrm{mg} / \mathrm{kg}$. Indocarbocyanine (Cy3)-192IgG (3-5 $\mu \mathrm{l} ; 0.4 \mathrm{mg} / \mathrm{ml})$ was stereotaxically injected unilaterally or bilaterally into the lateral ventricle of each rat with a Hamilton syringe (22 gauge needle) at a rate of $0.5 \mu \mathrm{l} / \mathrm{min}$. The coordinates used were as follows: $0.8 \mathrm{~mm}$ posterior from bregma, $1.2 \mathrm{~mm}$ lateral from the midline, and 3-4 $\mathrm{mm}$ below the dura. Two to $5 \mathrm{~d}$ later, slices were prepared from Cy3-192IgG-injected rats and used for electrophysiological recordings. Recordings from unlabeled neurons were restricted to animals injected biventricularly.

Retrograde labeling of septohippocampal neurons. In 14- to 21-d-old anesthetized rats (see above), retrograde labeling of septohippocampal neurons (SHNs) was performed by pressure-injecting 50-100 $\mathrm{nl}$ of rhodaminelabeled fluorescent latex microspheres (Lumafluor Inc., Naples, FL) at several sites within the hippocampus by the use of a glass micropipette (40-50 $\mu \mathrm{m}$ tip diameter). Rhodamine microspheres $(0.02-0.2 \mu \mathrm{m}$ diameter) show little diffusion and consequently produce small, sharply defined injection sites. After being transported back to neuronal somata, the label persists for at least 10 weeks in vivo and 1 year after fixation. Microspheres have been reported to possess no obvious cytotoxicity or phototoxicity as assessed by intracellular recording and staining of retrogradely labeled cells in a brain slice preparation (Katz et al., 1984). The stereotaxic coordinates were as follows (anteroposterior, lateral, and ventral): -2.8 , -1.4 , and $-2.8 ;-4,-1.4$, and -2.8 ; and $-5.8,-4.5$, and -3.5 to $-6 \mathrm{~mm}$ track. Two or more days later, the injected rats were used to prepare brain slices. Injection sites were confirmed for each experiment.

Fluorescence and infrared imaging. Infrared, differential interference contrast imaging (IR-DIC) was performed to visualize neurons for extracellular or patch-clamp recording using an Olympus Optical (Tokyo, Japan) BX-50 microscope equipped with a $60 \times$ water immersion objective (numerical aperture, 0.9; Olympus Optical). Images were detected with a CCD-300-RC camera (DAGE-MTI, Michigan City, IN) and displayed on a standard black-and-white video monitor (HR 120; DAGE-MTI). The images were transferred to the hard disk of a personal computer using an LG-3 scientific frame grabber (Scion Image Corp.; Frederick, MD) and processed further with Adobe Photoshop. Cy3-192IgG- and rhodaminelabeled neurons were visualized using the appropriate fluorescence filters, as was Lucifer yellow. A neuron viewed with infrared optics was considered to be the same as that viewed with fluorescence optics when the infrared image and the fluorescent image of the neuron had the same position and orientation with the two imaging systems.

Electrophysiology recordings. The image of the cells in the slice was displayed on a video monitor, and glass pipettes used for electrophysiological recordings were visually advanced through the slice to the surface of the cell from which recordings were made. Extracellular recordings were performed with glass micropipettes filled with $2 \mathrm{M} \mathrm{NaCl}(5-10 \mathrm{M} \Omega$ ). Whole-cell patch-clamp recordings were performed by the use of previously described methods (Alreja and Liu, 1996). In brief, low-resistance (2.5-3.5 $\mathrm{M} \Omega$ ) patch pipettes were filled with a solution containing (in $\mathrm{mM}$ ): $\mathrm{K}$ methylsulfonate/KCl, 120; HEPES, 10; BAPTA $\mathrm{K}_{4}$, 5; sucrose, 20; $\mathrm{CaCl}_{2}, 2.38 ; \mathrm{MgCl}_{2}, 1 ; \mathrm{K}_{2} \mathrm{ATP}, 1$ and GTP, 0.1, $\mathrm{pH}$ 7.32-7.35. All recordings were made with an Axoclamp-2B amplifier (Axon Instruments) in the bridge mode; the output signal was filtered at $10 \mathrm{kHz}$. The cells selected for study had spike amplitudes of $70-100 \mathrm{mV}$. Spike durations were measured at half-spike amplitude. In spontaneously firing cells, these measurements were done at the resting potential, and in quiescent cells, firing was evoked by injecting a small amount of depolarizing current. Voltage-clamp recordings were performed using the continuous single-electrode voltage-clamp mode. The firing rate, current, and voltage signals were amplified and continuously recorded on a chart recorder (Gould 2200). For intracellular labeling studies, Lucifer yellow $(1 \%)$ was added to the patch pipette solution.

Antidromic activation of septohippocampal neurons and extracellular recordings. Extracellular recordings were made from spontaneously firing MSDB neurons with glass micropipettes filled with $2 \mathrm{M} \mathrm{NaCl}(5-10 \mathrm{M} \Omega$ ), and the fornix was stimulated by the use of a bipolar Teflon-coated tungsten electrode. SHNs were identified by their antidromic response to electrical stimulation of the dorsal fornix (square pulses of $0.1-0.3 \mathrm{msec}$ duration; 40-1000 $\mu \mathrm{A}$ ) using the following criteria: fixed latency of activation and high frequency after and collision of the antidromic spikes with orthodromic spikes (see Fig. 4A,B). Similar criteria have been used previously to identify septohippocampal neurons in vitro (Alreja and Liu 1996; Liu et al., 1998; Alreja et al., 2000). The threshold of activation and the latency of antidromic activation were measured for each SHN, and the latency measurement was used to compute the conduction velocity for each SHN. The distance between the stimulating and the recording electrodes was measured by the use of a calibrated graticule located in the eyepiece of the dissection scope.

Double-labeling studies. To determine the phenotype of cells recorded with Lucifer yellow-containing patch pipette solutions, double-labeling studies were performed on slices fixed with $4 \%$ paraformaldehyde solution. For the choline acetyltransferase (ChAT) immunoreaction, the sections were incubated in a rat anti-ChAT primary antibody [1:5 dilution in phosphate buffer (PB); Boehringer Mannheim, Indianapolis, IN] overnight at room temperature. Subsequently, sections were incubated in rabbit anti-rat IgG labeled with Texas Red (1:100 in PB; Vector Laboratories, Burlingame, CA) for $2 \mathrm{hr}$ at room temperature in the dark. Immunofluorescence was visualized under an Olympus BX50WI scope (Olympus Optical, Tokyo, Japan) with the appropriate filters. Rhodamine beads appeared as granules within the cytoplasm of the cells, whereas the ChAT immunofluorescence was homogeneously distributed in the cells. This made it easy to confirm colocalization of the two substances in the same cell.

Materials. Acetylcholine chloride, muscarine chloride, atropine sulfate, and $(-)$-scopolamine hydrobromide were obtained from Research Biochemicals (Natick, MA). All drugs were diluted in ACSF from previously prepared stock solutions that were prepared in water and stored at $-20^{\circ} \mathrm{C}$. Rhodamine microspheres were obtained from Lumafluor (Naples, FL), and Cy3-192IgG was custom synthesized by Advanced Targeting Systems (San Diego, CA).

\section{RESULTS}

\section{Muscarinic antagonists inhibit MSDB neurons in vitro}

To determine whether the muscarinic tone that is observed in vivo is intrinsic to the MSDB, we tested the effects of the muscarinic receptor antagonists atr/scop on septohippocampal neurons in vitro in brain slices. The in vitro slice preparation, although retaining the cell bodies of the septohippocampal cholinergic neurons, is devoid of the brainstem neuronal cholinergic cell bodies that provide extrinsic cholinergic afferents to the MSDB. The presence of a tone in vitro would therefore suggest the involvement of locally released ACh. Several studies have shown that exogenously applied ACh or muscarine can produce both inhibitory and excitatory effects in MSDB neurons, a significant number of which are spontaneously firing (Dutar et al., 1983; Lamour et al., 1984; Segal, 1986; Liu et al., 1998). We therefore speculated that if a muscarinic tone were present in the MSDB in vitro then bath applications of atr/scop would have an effect opposite to that of the muscarinic agonists; i.e., atr/scop would either disinhibit or disfacilitate MSDB neurons, an effect that would be observed as an increase or decrease, respectively, in basal firing rates.

To test for the presence of a muscarinic tone in vitro in MSDB neurons, we first performed extracellular recordings on unidentified, spontaneously firing MSDB neurons and tested the effect of bath-applied $\mathrm{ACh} /$ muscarine and atr/scop on basal firing rates. Of the 36 cells tested with atr/scop (100 nM-3 $\mu \mathrm{M} ; 10-20 \mathrm{~min} ; n=21$ for atropine and $n=15$ for scopolamine), 35 neurons were excited by $\mathrm{ACh} /$ muscarine, and 1 was inhibited by $\mathrm{ACh} /$ muscarine. Interestingly, in $52.8 \%$ of the neurons excited by $\mathrm{ACh} /$ muscarine (19 of 36), bath-applied atr/scop produced a striking reduction or even a complete cessation of basal firing (11 of 19 neurons tested; Fig. $1 A)$, suggesting that a muscarinic tone is indeed present in the MSDB in vitro. Thus, atropine reduced basal firing rates from a mean rate of $4.5 \pm 1.5 \mathrm{~Hz}$ to a rate of $1 \pm 0.3 \mathrm{~Hz}(n=9)$, and scopolamine reduced the baseline firing from $5.6 \pm 0.4$ to $2 \pm 0.37$ 
A

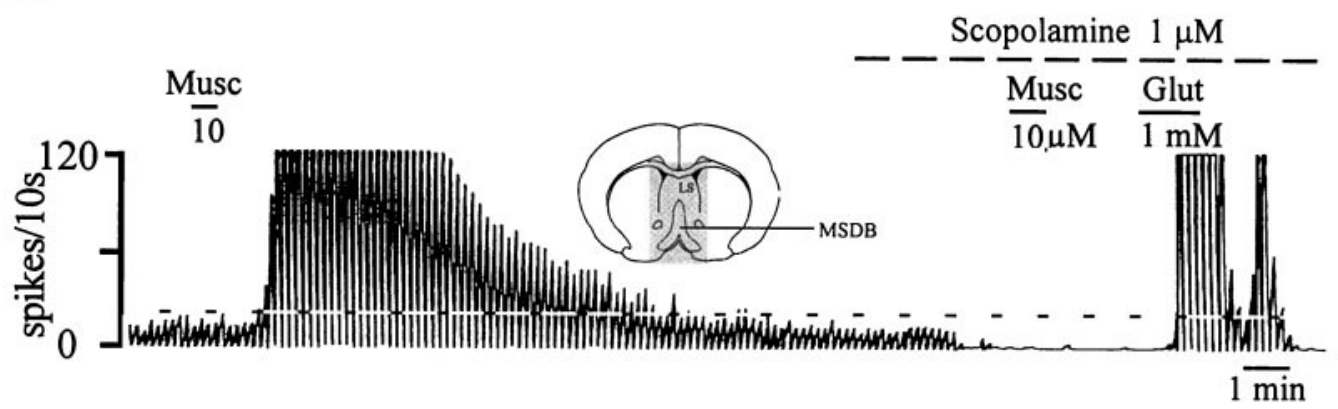

B
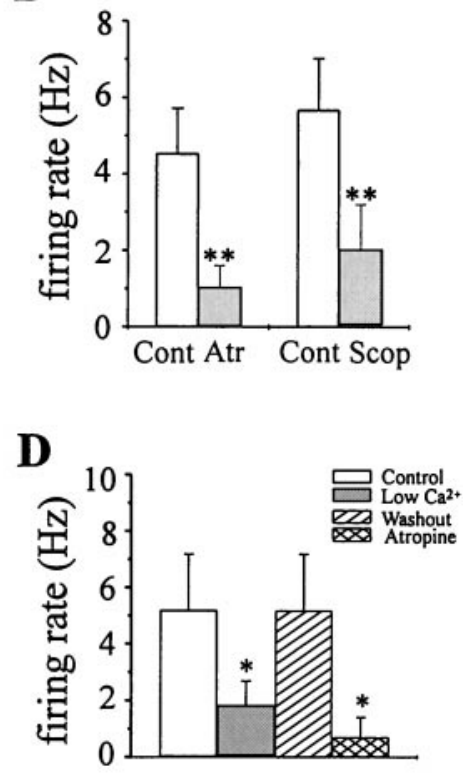

C

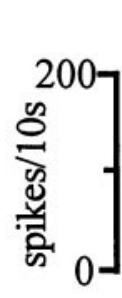

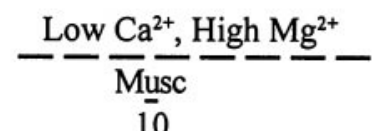

10

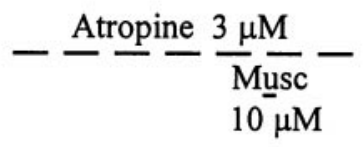

$2 \min$

Figure 1. A muscarinic tone is present in the MSDB in vitro. A, Extracellular recording from an MSDB neuron shows that muscarine (Musc) produced a profound increase in firing rate. Scopolamine, a muscarinic receptor antagonist, reduced the basal firing rate and blocked the effect of muscarine; the cell still responded to glutamate (Glut) with a strong excitation. Inset, A coronal section of the brain at the level of the septal nucleus is shown. The slice preparation was restricted to the stippled area. B, A summary is shown of the effect of atropine (Atr) and scopolamine (Scop) on the basal firing rate of neurons that responded to ACh with an increase in firing rate. Thus, MSDB neurons are under a constant muscarinic tone, presumably because of the presence of locally released $\mathrm{ACh}$. $\mathrm{C}$, A blockade of synaptic transmission, using a low-C $\mathrm{Ca}^{2+}$, high- $\mathrm{Mg}^{2+}$-containing external solution, also reduced basal firing rates but did not block the excitatory effects of exogenously applied agonist. Atropine both reduced basal firing and blocked the excitatory effects of muscarine. $D$, A summary of the effect of blocking synaptic transmission on basal firing rates in MSDB neurons is shown. Cont, Control. * $p<0.05$. Horizontal dashed line indicates baseline firing.

$\mathrm{Hz}(n=10 ; p<0.001$, Student's paired $t$ test $)$. Atr/scop also blocked the effects of exogenous ACh/muscarine but had no effect in neurons not affected by $\mathrm{ACh} /$ muscarine $(n=4)$.

In agreement with a possible role for synaptic transmission in the regulation of basal firing rates, external solutions containing low $\mathrm{Ca}^{2+}$ and high $\mathrm{Mg}^{2+}$ (which block synaptic transmission) also produced a reversible decrease or cessation in basal firing in three of three neurons that were subsequently inhibited by atr/scop. The response to exogenous muscarine, which does not depend on synaptic transmission, remained intact in low- $\mathrm{Ca}^{2+}$ and high- $\mathrm{Mg}^{2+}$ solutions (Fig. 1C).

\section{Spontaneously firing cholinergic neurons are present within the MSDB}

We next confirmed the presence of spontaneously firing cholinergic neurons within the MSDB in our brain slices because the presence of such neurons would be critical for the generation of a muscarinic tone in vitro. Septohippocampal cholinergic neurons were identified in brain slices either in the living state by using a novel fluorescent marker, Cy3-192IgG, or in the fixed state after completion of the experiment using the technique of double immunolabeling. $\mathrm{Cy3}-$ 192IgG is a conjugate of the inert fluorochrome $\mathrm{Cy} 3$ and of 192IgG, an antibody against the p75 neurotrophin receptor. When injected intraventricularly, Cy3-192IgG retrogradely labels only p75 receptor-expressing neurons (Hartig et al., 1998), which in the MSDB are exclusively cholinergic. In a recent study, we confirmed the specificity of Cy3-192IgG and also found that the presence of Cy3-192IgG in living cholinergic neurons alters neither their electrophysiological properties nor their responsivity to muscarinic agonists (Wu et al., 2000).

In brain slices viewed with an IR-DIC microscope equipped for fluorescence, Cy3-192IgG-labeled neurons appeared as red fluorescent neurons with a punctate-type staining (Fig. $2 A$, left). As noted previously, Cy3-192IgG-labeled neurons had a healthy appearance (Fig. 2A, right), and 55\% (39 of 71) of these neurons fired spontaneously (Fig. $2 B$ ) at a mean rate of $2.1 \pm 0.3 \mathrm{~Hz}$ recorded extracellularly. Whole-cell recordings established in $70 \%$ of the neurons confirmed the presence of an electrophysiological signature typical of cholinergic neurons (Fig. $2 C$ ). In brain slices prepared from uninjected rats, neurons with electrophysiological characteristics of cholinergic neurons (Griffith and Matthews, 1986; Markram and Segal, 1990; Gorelova and Reiner, 1996) also displayed similar spontaneous firing activity (data not shown).

Finally, recordings were also made in brain slices taken from rats in which the inert retrograde tracer rhodamine coated on latex microspheres was injected into the hippocampus $2 \mathrm{~d}$ before recording (Fig. 2E). Rhodamine beads label both septohippocampal cholinergic and septohippocampal GABAergic neurons. After recording of the basal firing rates, rhodamine-labeled cells were impaled and filled with the intracellular marker Lucifer yellow (Fig. 2D, top). Double-labeling studies, using an antibody against ChAT, were used to determine whether the recorded cell was cholinergic. Three of three double-labeled, retrogradely marked septohippocampal cholinergic neurons (Fig. 2D, bottom) also fired spontaneously at a rate of $3.8 \pm 2.2 \mathrm{~Hz}$. Thus, spontaneously firing septohippocampal cholinergic neurons, which could theoretically release ACh tonically via axon collaterals, are present within the MSDB.

\section{Muscarinic receptor antagonists inhibit noncholinergic MSDB neurons}

Having demonstrated the presence of muscarinic tone in vitro, we next determined the effects of atr/scop on identified septohippocampal cholinergic and septohippocampal noncholinergic neurons. As mentioned above, septohippocampal cholinergic neurons are either inhibited or not affected by $\mathrm{ACh} /$ muscarine (Wu et al., 2000). Theoretically therefore, if a muscarinic tone was present on cholinergic neurons, then atr/scop should disinhibit these neurons, that is, increase their basal firing rate. Consistent with our recent findings, cholinergic neurons, as identified by Cy3-192IgG labeling, 

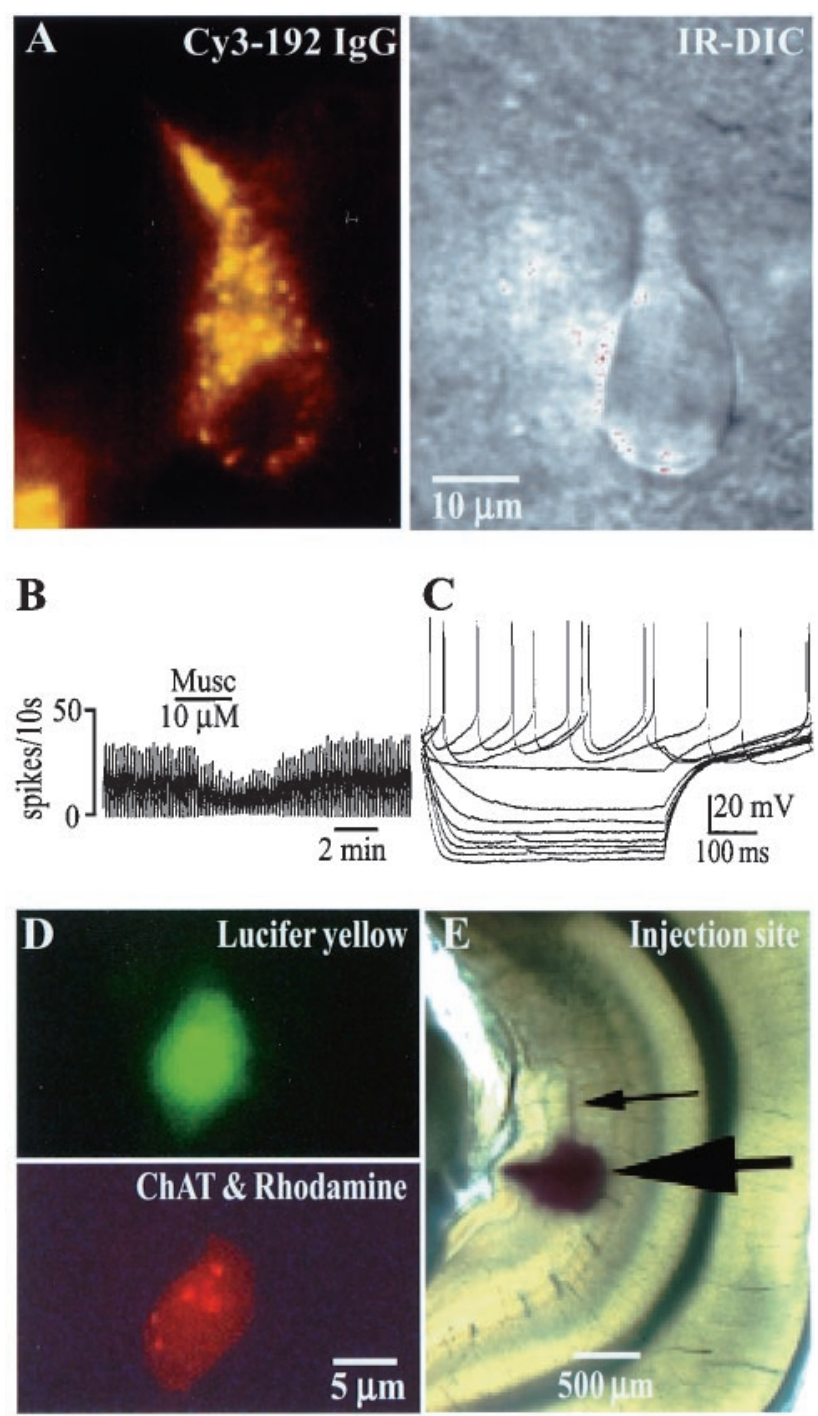

Figure 2. Spontaneously firing cholinergic neurons are present in the MSDB in vitro in brain slices. A, Left, A Cy3-192IgG-labeled neuron visualized in a living brain slice is shown. Cy3-192IgG labels only cholinergic neurons within the MSDB (Hartig et al., 1998; Wu et al., 2000). Right, An IR-DIC image of the same cell shows its healthy appearance. $B$, Extracellular recordings from a spontaneously firing Cy3-192IgG-labeled neuron that was inhibited by muscarine are shown. Fifty-five percent of the Cy3-labeled cholinergic neurons recorded from fired spontaneously. $C$, Electrophysiological signature of a Cy3-192IgG-labeled neuron obtained in response to depolarizing and hyperpolarizing pulses (step size, $0.2 \mathrm{nA}$; maximum step, $+0.4 \mathrm{nA}$ ) is shown. $D$, A triple-labeled septohippocampal cholinergic neuron that also fired spontaneously (data not shown) is shown. The cell was labeled with Lucifer yellow after establishment of whole-cell recording. Subsequently, the cell also tested positive for choline acetyltransferase (diffuse red stain), a marker of cholinergic neurons. $E$, This neuron also colocalized the retrograde marker rhodamine beads (red dots marked by arrows), which were injected into the hippocampus in vivo, $2 \mathrm{~d}$ before slicing.

were inhibited or not affected by ACh/muscarine (Wu et al., 2000). Of the 14 Cy3-labeled neurons inhibited by $\mathrm{ACh} /$ muscarine, 8 fired spontaneously at a rate of $2.7 \pm 0.4 \mathrm{~Hz}$; muscarine reduced their rate to $0.6 \pm 0.3 \mathrm{~Hz}$. The remaining 6 neurons were quiescent and showed a $1.4 \pm 0.24 \mathrm{mV}$ hyperpolarization in response to $\mathrm{ACh} /$ muscarine. Interestingly only 1 of $14 \mathrm{Cy} 3$-labeled neurons responded to atr/scop with a small increase in firing rate (data not shown). Thus, contrary to current thinking, intraseptal atropine would not decrease hippocampal ACh release. It may, however, increase hippocampal ACh release (Fig. $3 A$ ).

In contrast to the Cy3-192IgG-labeled neurons mentioned above, Cy3-192IgG-unlabeled neurons, which are predominantly
A Cy3-192IgG-labeled neuron

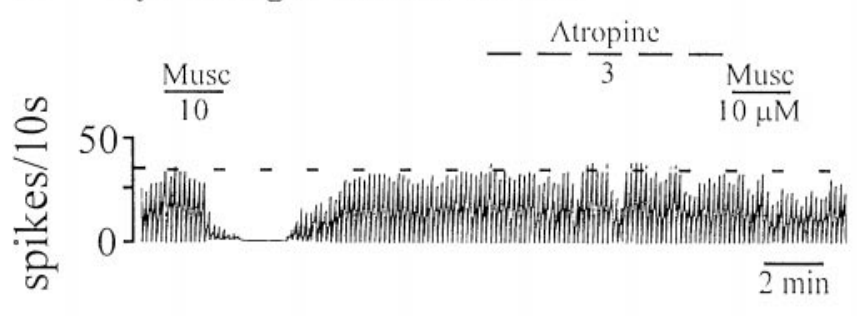

B Cy3-192IgG-unlabeled neuron
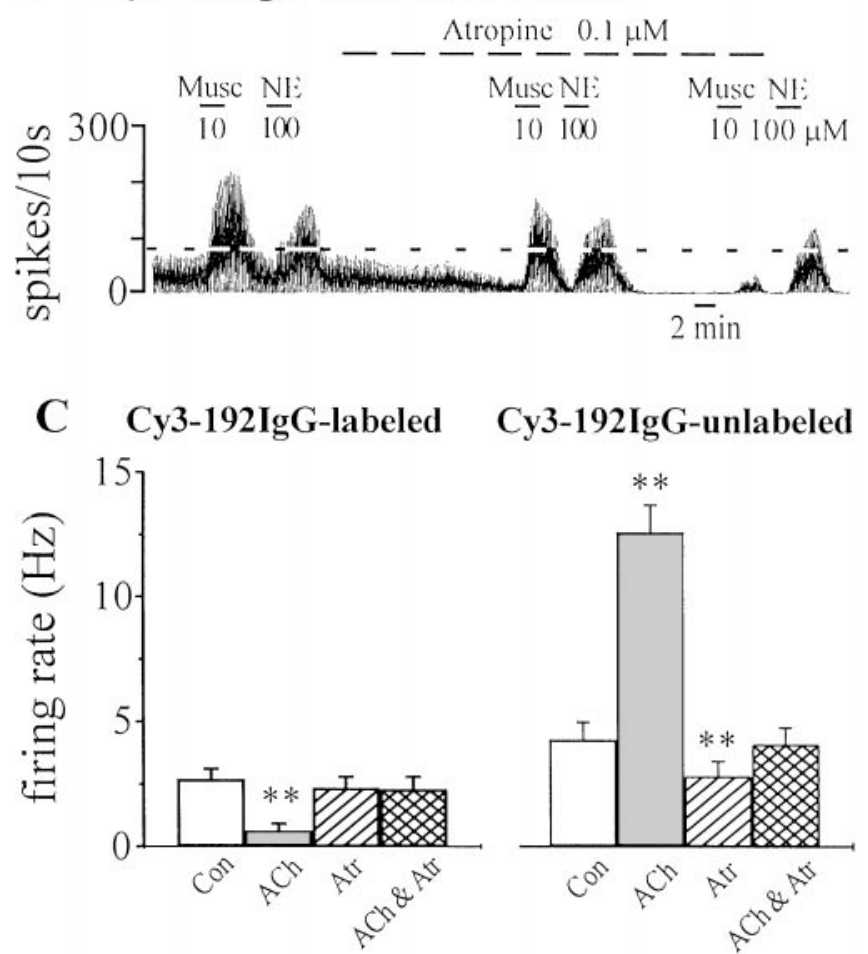

Figure 3. Effect of muscarinic receptor antagonists on Cy3-192IgGlabeled and unlabeled MSDB neurons. $A$, Recording from a Cy3-192IgGlabeled cholinergic neuron shows that although atropine $(3 \mu \mathrm{M})$ had no effect on the baseline firing rate, it did block the inhibitory effect of exogenously applied muscarine. B, In contrast, in a Cy3-192IgG-unlabeled neuron (presumably, GABAergic), a low nanomolar concentration of atropine reduced basal firing rates and also blocked the effect of exogenous muscarine but had little effect on norepinephrine $(N E)$-induced excitation; $N E$ has been shown previously to excite septohippocampal GABA neurons (Alreja and Liu, 1996). C, The bar chart summarizes the effects of muscarinic drugs on Cy3-192IgG-labeled (i.e., cholinergic) and Cy3-192IgGunlabeled neurons. Note that atropine had no effect on Cy3-labeled neurons; unlabeled neurons that are excited by muscarine show a decrease in basal firing rates in the presence of atropine. Con, Control. ${ }^{*} p<<0.005$.

GABAergic (local or projection) and respond to $\mathrm{ACh} / \mathrm{muscarine}$ with an excitation (Wu et al., 2000), were strongly inhibited by atr/scop (Fig. 3B). The inhibitory effect of atr/scop on basal firing was observed as a $66.2 \pm 10.6 \%$ decrease in basal firing rate in $47 \%$ (8 of 17) of the Cy3-192IgG-unlabeled neurons tested (Fig. 3C). Overall, in the Cy3-192IgG-unlabeled neuronal population, the control rate was $4.2 \pm 0.7 \mathrm{~Hz}$, and it changed to $2.8 \pm 0.6 \mathrm{~Hz}$ after atr/scop $(p<0.005 ; n=17)$. Thus, a subpopulation of GABAergic neurons in the MSDB is inhibited by atr/scop.

\section{Noncholinergic MSDB neurons that are inhibited by atr/ scop project to the hippocampus}

Because a subpopulation of GABAergic neurons in the MSDB projects to the hippocampus (Wu et al., 2000), we hypothesized that the neurons that are inhibited by atr/scop might also project to the hippocampus. To test this hypothesis, we studied the effects of atr/scop on septohippocampal GABA neurons that were retro- 
A
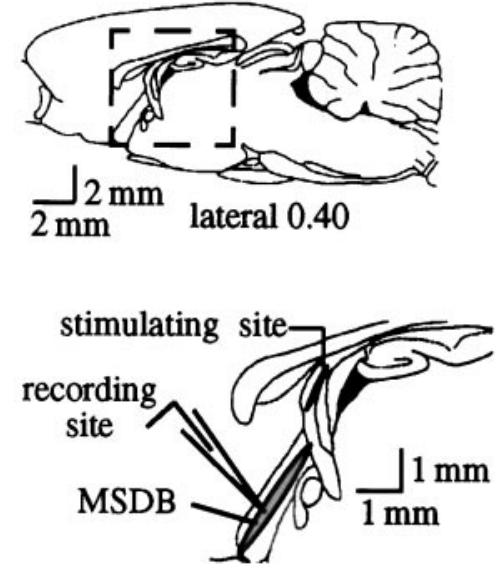

B

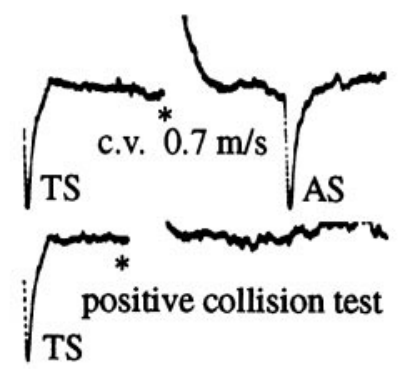

E

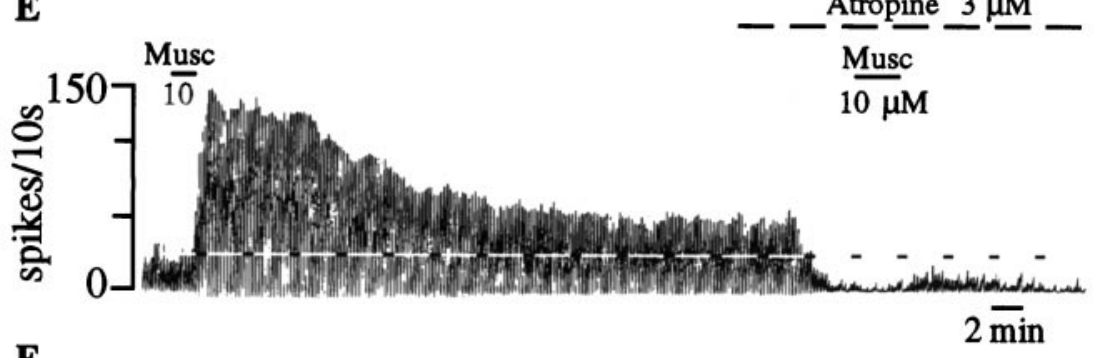

F
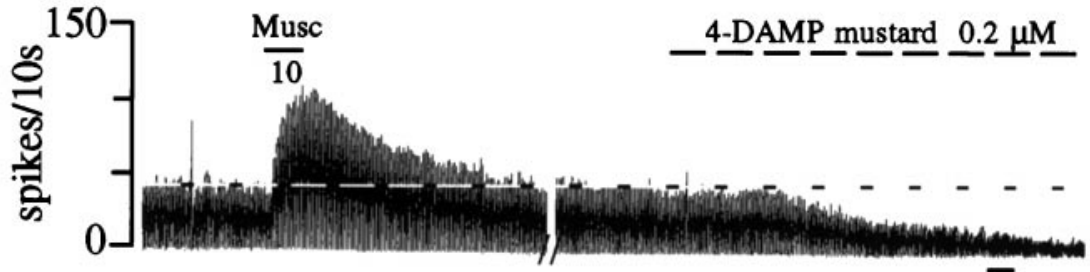

$2 \overline{\min }$

4-DAMP mustard $0.2 \mu \mathrm{M}$
C

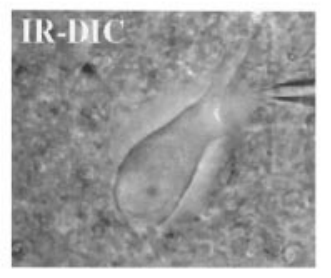

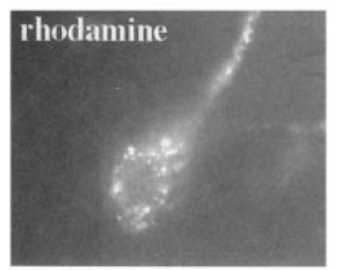

G

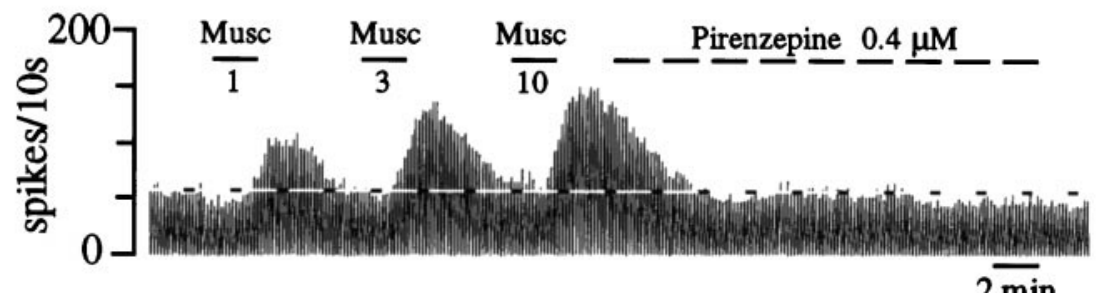

D

H

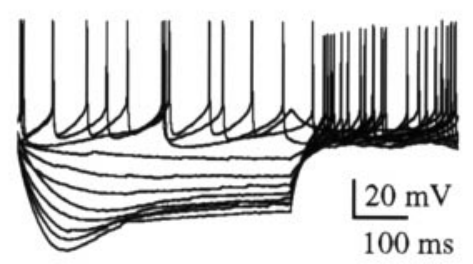

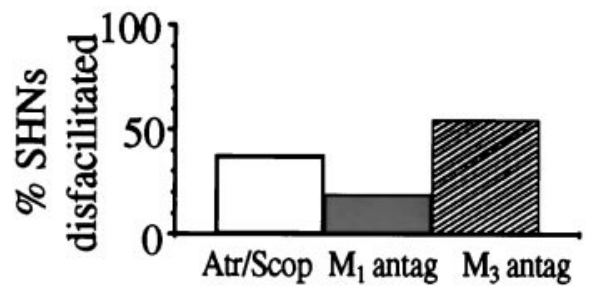

Figure 4. Effect of muscarinic receptor antagonists on septohippocampal neurons. A, Top, Sagittal section through the rat brain shows the septal area. Bottom, The boxed area in the top panel is enlarged and shows the MSDB that was the recording site. For antidromic identification of septohippocampal neurons, the stimulating electrode was placed in the dorsal fornix because it conveys both cholinergic and GABAergic MSDB fibers to the hippocampus. $B$, Top, Extracellular recording from a spontaneously firing, antidromically activated septohippocampal neuron is shown. A spontaneous spike was used to trigger the oscilloscope $(T S)$, the dorsal fornix was stimulated $\left.*^{*}\right) 4$ msec later, and an antidromically activated spike $(A S)$ was obtained after a latency of $3.3 \mathrm{msec}$. This cell was classified as a GABA type on the basis of the calculated conduction velocity of $0.7 \mathrm{~m} / \mathrm{sec}$. Bottom, A positive collision test, in which the cell could not be activated antidromically when the dorsal fornix was stimulated $3 \mathrm{msec}$ after the triggering spike, is shown. For additional criteria used for confirming antidromicity, see Alreja and Liu (1996). C, An IR-DIC image is shown of a septohippocampal neuron identified using the retrograde tracer rhodamine beads that were injected into the hippocampus $2 \mathrm{~d}$ before recording. $D$, Electrophysiological signature of a rhodamine-labeled neuron is obtained in response to depolarizing and hyperpolarizing pulses (step size, $0.2 \mathrm{nA}$; maximum step, $+0.4 \mathrm{nA}$ ). Note the depolarizing sag that is characteristic of septohippocampal GABA but not cholinergic neurons. This neuron was excited by muscarine (data not shown), a property that is exclusive to noncholinergic MSDB neurons. $E$, The chart record shows that bath-applied muscarine produced a profound and prolonged increase in the firing rate in an SHN. Atropine, a muscarinic receptor antagonist, reduced basal firing and blocked the response to a subsequent application of muscarine. $F$, Low nanomolar concentrations of 4-DAMP mustard, an $\mathrm{M}_{3}$-selective antagonist, reduced basal firing and also blocked the effects of exogenous muscarine (data not shown). $G$, The concentration-dependent excitatory effect of muscarine in another SHN is shown. Pirenzepine, an $\mathrm{M}_{1}$-selective antagonist, had no effect on the basal firing rate. $H$, The effects of antagonists are summarized. Although atr/scop and the $\mathrm{M}_{3}$-selective antagonist reduced basal firing rates in $40-50 \%$ of the neurons tested, the $\mathrm{M}_{1}$ antagonist had an effect in $20 \%$ of the neurons tested. Antag, Antagonist.

gradely labeled with rhodamine beads. If a rhodamine-labeled neuron responded to $\mathrm{ACh} /$ muscarine with an excitation, then it was assumed to be a septohippocampal GABAergic neuron because septohippocampal cholinergic neurons are not excited by muscarine (Wu et al., 2000). Atr/scop decreased basal firing by $73.6 \pm$ $19 \%$ in $39 \%$ of septohippocampal GABA-type neurons identified by these criteria ( $n=8$; Fig. $4 E$ ). Whole-cell recordings further confirmed the neurons to be septohippocampal GABA-type on the basis of electrophysiological criteria (Fig. 4D) (Morris et al., 1999). The remaining neurons were not affected by atr/scop. Thus, a muscarinic tone is present on septohippocampal GABA neurons in vitro.

\section{An $M_{3}$ receptor antagonist mimics the inhibitory effects of atr/scop on septohippocampal neurons}

Because of the critical importance of the muscarinic tone in the MSDB in cognitive functioning, we next determined the specific receptor subtype(s) that might be involved in mediating the effects of endogenous ACh on septohippocampal GABA-type neurons. In a previous study we had found that the excitatory effects of exogenously applied muscarinic agonists in septohippocampal neurons are mediated primarily via the non- $\mathrm{M}_{1}$ subtype of receptors. Involvement of the $\mathrm{M}_{3}$ and possibly the $\mathrm{M}_{5}$ subtype of muscarinic 
receptors was indicated (Liu et al., 1998). These findings were strongly supported by the absence of $\mathrm{M}_{1}$ receptor immunoreactivity as well as mRNA (Buckley et al., 1988; Vilaro et al., 1994) and an abundance of $\mathrm{M}_{3}$ mRNA (Vilaro et al., 1994) and immunoreactivity (Levey et al., 1994; Rouse and Levey, 1996) in septohippocampal neurons. Low levels of $\mathrm{M}_{5}$ mRNA are also present in the MSDB (Vilaro et al., 1990).

We, therefore, tested the effects of 4-DAMP mustard (an $\mathrm{M}_{3}$ selective antagonist) as well as of pirenzepine and telenzepine $\left(\mathrm{M}_{1}\right.$-selective receptor antagonists) on basal firing rates of MSDB neurons, some of which were confirmed to be septohippocampal by the use of either the technique of retrograde marking or the technique of antidromic activation (Fig. $4 A, B$ ) in sagittal slices. The role of $\mathrm{M}_{5}$ receptors in mediating the muscarinic tone in MSDB neurons could not be studied because an $\mathbf{M}_{5}$-selective antagonist is not yet available. As expected on the basis of our previous study (Wu et al., 2000), low nanomolar concentrations of 4-DAMP mustard, an irreversible antagonist that selectively inactivates $M_{3}$ receptors but has no effect on $M_{1}, M_{2}, M_{4}$, and $M_{5}$ receptors (see Liu et al., 1998), reduced basal firing rates in $55 \%$ of the neurons tested ( 6 of 11). Of the 6 neurons that were inhibited by 4-DAMP mustard, 3 were confirmed to be septohippocampal neurons (Fig. $4 F, H$ ), a percentage similar to that observed with atr/scop (Fig. 4H). The change in basal firing rates was statistically significant (control rate, $3.2 \pm 1 \mathrm{~Hz}$; after $\mathrm{M}_{3}$ antagonist, $0.6 \pm 0.5$ $\mathrm{Hz}$; Fig. $4 F, H)$. The $\mathrm{M}_{1}$ receptor-selective antagonists pirenzepine and telenzepine also reduced basal firing rates in $19 \%$ of cells tested ( 3 of 16); 2 of 3 neurons were confirmed to be septohippocampal neurons. However, the reduction in basal firing rate was statistically insignificant (control rate, $2.8 \pm 1.3 \mathrm{~Hz}$; after $\mathrm{M}_{1}$ antagonist, $0.1 \pm 0.05 \mathrm{~Hz}$; Fig. $4 G, H)$. Thus, $\mathrm{M}_{3}$ receptors contribute to the muscarinic tone in the MSDB, suggesting that $M_{3}$ receptor agonists could be beneficial in treating cognitive deficits that are associated with a loss of muscarinic tone in the MSDB.

\section{DISCUSSION}

In the present study we have demonstrated two key features about the muscarinic tone in the MSDB. First, the muscarinic tone in the MSDB is caused by a tonic release of ACh that occurs from within the MSDB, presumably via axon collaterals of spontaneously firing septohippocampal cholinergic neurons. Second, the locally released $\mathrm{ACh}$ in the MSDB provides a profound excitatory drive to the septohippocampal GABA neurons but has little or an opposing effect on the septohippocampal cholinergic neurons. Thus, the memory-impairing effects of muscarinic receptor antagonists cannot be attributed to a decrease in hippocampal ACh release. Instead, a decrease in septohippocampal GABA release may underlie the effects of muscarinic receptor antagonists on cognitive functions.

\section{A muscarinic tone is intrinsic to the MSDB}

Behavioral studies have long documented the presence of a muscarinic tone in the brain of various species; a blockade of this tone produces amnesia. As mentioned in the introductory remarks, experimental studies indicate that the MSDB may be a key locus for the mnemonic effects of muscarinic antagonists. The present study using electrophysiological recording techniques in rat brain slices not only confirms the presence of such a tone in single MSDB neurons but provides evidence that the muscarinic tone is produced from within the MSDB. This tone presumably originates from the septohippocampal cholinergic neurons present within the MSDB, which have anatomically been demonstrated to send collaterals to neurons within the MSDB (Brauer et al., 1998). By the use of two different techniques of identification, $55 \%$ of cholinergic neurons in our brain slice preparations were found to be spontaneously firing and therefore capable of releasing ACh locally in an impulse-dependent manner. Accordingly, a blockade of synaptic transmission, using low- $\mathrm{Ca}^{2+}$, high- $\mathrm{Mg}^{2+}$ external solutions, was also found to mimic the effects of muscarinic receptor antagonists and inhibit a subpopulation of MSDB neurons. The presence of spontaneously firing cholinergic neurons within the MSDB that are capable of releasing acetylcholine under basal conditions is consistent with microdialysis data obtained both in vivo and in vitro, in which impulse-dependent $\mathrm{ACh}$ release has been recorded both locally within the septum and in the hippocampus (Moor et al., 1994).

Because the present study was performed in younger rats, it is possible that the muscarinic tone demonstrated in this study may be of a different magnitude in animals of different ages, possibly because of factors such as the pruning of axon collaterals or a loss of cholinergic neurons with age. In this regard, it should be mentioned that microdialysis studies have detected higher ACh release in septal slices taken from 2.5- to 3-month-old rats compared with that of 2-week-old rats (Disko et al., 1999). Whether basal ACh release is reduced in the septum of aged rats (22-24 week rats) is not known. However, because hippocampal ACh release is clearly reduced in aged rats (Vannucchi et al., 1997), septal ACh release is likely to be reduced too. Additionally, because behavioral deficits in mnemonic functions that occur in aged animals can be reversed by intraseptal applications of muscarinic agonists (Markowska et al., 1995), the intraseptal muscarinic tone is likely to be reduced in aged animals.

It is conceivable that $\mathrm{ACh}$ released via the extrinsic brainstem afferents may also contribute to the muscarinic tone in the MSDB in vivo both in young and aged rats. If so, then muscarinic receptor antagonists would produce an even greater decrease in septohippocampal GABA transmission. Septohippocampal cholinergic transmission, on the other hand, could get enhanced as cholinergic neurons are inhibited by muscarine (Wu et al., 2000).

\section{The muscarinic tone in the MSDB provides an excitatory drive to the septohippocampal GABA but not to the septohippocampal cholinergic neurons}

A second major finding of this study is that the muscarinic tone in the MSDB provides a profound excitatory drive to the noncholinergic septohippocampal GABAergic-type neurons but has little or an opposing effect on the septohippocampal cholinergic neurons. Thus, only 1 of 14 cholinergic neurons identified by the use of the selective fluorescent marker Cy3-192IgG responded to atr/scop with an increase in firing rate, whereas $47 \%$ of Cy3-192IgGunlabeled neurons (which are primarily GABAergic), some of which were confirmed to be septohippocampal, were strongly inhibited by atr/scop. These findings are consistent with the presence of ChAT-immunoreactive terminals contacting nonimmunoreactive perikarya in the MSDB that suggests a cholinergic innervation of noncholinergic MSDB neurons (Bialowas and Frotscher, 1987) and with the more recent demonstration of local cholinergic boutons contacting parvalbumin-containing septohippocampal GABAergic neurons (Brauer et al., 1998).

Thus, contrary to current thinking, intraseptal atropine would not decrease hippocampal ACh release. It may, however, increase hippocampal ACh release. These findings are consistent with the reported increase in hippocampal $\mathrm{ACh}$ release after intraseptal atropine in microdialysis studies (Moor et al., 1995). Thus, the amnesic effects of intraseptal atr/scop and possibly systemic atr/scop cannot be attributed to a decrease in ACh release in the hippocampus. Instead, a decrease in septohippocampal GABA release, via a disinhibitory mechanism (see below), may mediate the amnesic effects of muscarinic receptor antagonists.

Similar to muscarinic receptor antagonists, opioids, acting via $\mu$ receptors, also inhibit a subpopulation of septohippocampal GABA neurons, and interestingly intraseptal infusions of opioids impair performance in learning and memory tasks (see Alreja et al., 2000).

\section{$M_{3}$ receptors contribute to the effects of muscarinic receptor antagonists in the MSDB}

Another important finding of this study is that locally released ACh maintains impulse flow in the septohippocampal GABA pathway in part via $\mathrm{M}_{3}$ muscarinic receptors. Thus, an $\mathrm{M}_{3}$ receptor antagonist was found to mimic the effects of atr/scop in a subpopulation of 


\section{Hippocampus}

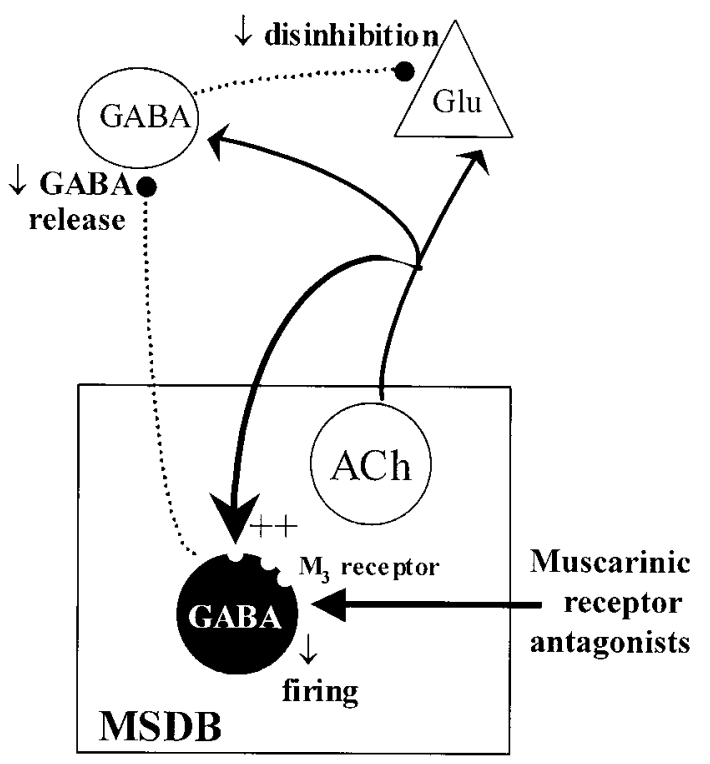

Figure 5. Schematic figure shows that ACh released via axon collaterals of septohippocampal cholinergic neurons provides an excitatory drive to the septohippocampal GABA neurons partly via $\mathrm{M}_{3}$ receptors. The muscarinic receptor antagonists atropine or scopolamine block this muscarinic tone and reduce impulse flow in the disinhibitory septohippocampal GABA pathway. ++ , excitation.

MSDB neurons in brain slices. This conclusion is consistent with the presence of $\mathrm{M}_{3}$ receptor message in SHNs (Levey et al., 1994; Vilaro et al., 1994; Rouse and Levey, 1996) and with our previous finding in which effects of exogenous $\mathrm{ACh} /$ muscarine in septohippocampal GABA-type neurons were also blocked by an $\mathrm{M}_{3}$ selective antagonist (Liu et al., 1998). The relatively weaker effects observed with $\mathrm{M}_{1}$ antagonists in this study are also consistent with the rather low levels of $M_{1}$ receptor message in MSDB neurons (Buckley et al., 1988; Vilaro et al., 1994). Involvement of $\mathbf{M}_{5}$ or other as yet undiscovered muscarinic receptors is also likely but cannot be tested at the present time because of lack of adequate tools. Because of the reported involvement of $\mathrm{M}_{1}$ receptors in mediating muscarinic responses in the hippocampus, the last decade witnessed the development of various $\mathrm{M}_{1}$-selective agonists. Our results suggest that $\mathrm{M}_{3}$-selective agonists may be even more beneficial for improvement of cognitive deficits. As such it would be interesting to determine whether a functional loss of $\mathrm{M}_{3}$ receptors would mimic the amnesic effects of atr/scop in behavioral studies.

\section{Implications of the findings}

A muscarinic receptor antagonist-induced decrease in septohippocampal GABA release could, theoretically, disinhibit large numbers of hippocampal GABAergic neurons and increase both the feedback and feedforward type of local hippocampal inhibition of pyramidal cells (Freund and Antal, 1988; Toth et al., 1997) because septohippocampal GABA neurons selectively innervate only the GABA interneurons in the hippocampus (Freund and Antal, 1988; Miettinen and Freund, 1992) (Fig. 5). In a long-term potentiation (LTP)-based model of learning and memory, such an effect would translate into a decreased likelihood for the induction of LTP, because LTP is preferentially induced when the pyramidal cells are maximally stimulated (Pavlides et al., 1988).

Thus, the present study demonstrates that septohippocampal cholinergic neurons, by providing an excitatory drive to the septohippocampal GABA pathway, play a much more powerful role in septohippocampal physiology than has been suspected previously and that the septohippocampal GABA rather than the cholinergic pathway is a key player in mediating the mnemonic effects of muscarinic drugs. Thus, an improvement or impairment in performance of septohippocampal-related learning and memory tasks can occur without an accompanying increase or decrease, respectively, in hippocampal ACh release. The reported findings thus suggest a fundamental revision in our understanding of the septohippocampal mechanisms that may underlie learning and memory functions.

Additionally, because the muscarinic tone in the MSDB originates from within the MSDB, a loss of septohippocampal cholinergic neurons, as occurs in normal aging, Alzheimer's disease, Parkinson's disease, Lewy body dementia, Down syndrome, and Korsakoff's disease, would not only decrease the direct excitatory effects of ACh in the hippocampus (by decreasing ACh release) but would also reduce the muscarinic tone within the MSDB and therefore severely disable both the cholinergic and GABAergic limbs of the septohippocampal pathway. Restoration of cholinergic function both in the hippocampus and the septum may, therefore, be critical for successful treatment of cognitive deficits associated with various neurodegenerative disorders. An $\mathrm{M}_{3}$ receptor agonist may prove useful in this regard provided the septohippocampal GABA neurons are still functional. It may therefore be worthwhile to determine the status of the parvalbumin-containing septohippocampal GABAergic neurons in postmortem brains derived from patients with such neurodegenerative disorders.

\section{REFERENCES}

Alreja M, Liu W (1996) Noradrenaline induces IPSCs in rat medial septal/ diagonal band neurons: involvement of septohippocampal GABAergic neurons. J Physiol (Lond) 494:201-215.

Alreja M, Shanabrough M, Liu W, Leranth C (2000) Opioids suppress IPSCs in neurons of the rat medial septum/diagonal band of Broca: involvement of mu-opioid receptors and septohippocampal GABAergic neurons. J Neurosci 20:1179-1189.

Arendt T, Bruckner MK, Bigl V, Marcova L (1995) Dendritic reorganisation in the basal forebrain under degenerative conditions and its defects in Alzheimer's disease. II. Ageing, Korsakoff's disease, Parkinson's disease, and Alzheimer's disease. J Comp Neurol 351:189-222.

Bartus RT (1978) Evidence for a direct cholinergic involvement in the scopolamine-induced amnesia in monkeys: effects of concurrent administration of physostigmine and methylphenidate with scopolamine. Pharmacol Biochem Behav 9:833-836.

Bialowas J, Frotscher M (1987) Choline acetyltransferase-immunoreactive neurons and terminals in the rat septal complex: a combined light and electron microscopic study. J Comp Neurol 259:298-307.

Brauer K, Seeger G, Hartig W, Rossner S, Poethke R, Kacza J, Schliebs R, Bruckner G, Bigl V (1998) Electron microscopic evidence for a cholinergic innervation of GABAergic parvalbumin-immunoreactive neurons in the rat medial septum. J Neurosci Res 54:248-253.

Buckley NJ, Bonner TI, Brann MR (1988) Localization of a family of muscarinic receptor mRNAs in rat brain. J Neurosci 8:4646-4652.

Deutsch JA, Rocklin KW (1967) Amnesia induced by scopolamine and its temporal variations. Nature 216:89-90.

Disko U, Haaf A, Gazyakan E, Heimrich B, Jackisch R (1999) Postnatal development of muscarinic autoreceptors in the rat brain: lateral and medial septal nuclei and the diagonal band of Broca. Brain Res Dev Brain Res 114:1-8.

Dutar P, Lamour Y, Jobert A (1983) Acetylcholine excites identified septo-hippocampal neurons in the rat. Neurosci Lett 43:43-47.

Freund TF, Antal M (1988) GABA-containing neurons in the septum control inhibitory interneurons in the hippocampus. Nature 336:170-173.

Givens B, Olton DS (1994) Local modulation of basal forebrain: effects on working and reference memory. J Neurosci 14:3578-3587.

Givens B, Olton DS (1995) Bidirectional modulation of scopolamineinduced working memory impairments by muscarinic activation of the medial septal area. Neurobiol Learn Mem 63:269-276.

Givens B, Sarter M (1997) Modulation of cognitive processes by transsynaptic activation of the basal forebrain. Behav Brain Res 84:1-22.

Gorelova N, Reiner PB (1996) Role of the afterhyperpolarization in control of discharge properties of septal cholinergic neurons in vitro. J Neurophysiol 75:695-706.

Griffith WH, Matthews RT (1986) Electrophysiology of AChE-positive neurons in basal forebrain slices. Neurosci Lett 71:169-174.

Hartig W, Seeger J, Naumann T, Brauer K, Bruckner G (1998) Selective in vivo fluorescence labelling of cholinergic neurons containing p75(NTR) in the rat basal forebrain. Brain Res 808:155-165.

Izquierdo I (1989) Mechanism of action of scopolamine as an amnesic. Trends Pharmacol Sci 10:175-177.

Katz LC, Burkhalter A, Dreyer WJ (1984) Fluorescent latex microspheres as a retrograde neuronal marker for in vivo and in vitro studies of visual cortex. Nature 310:498-500.

Kopelman MD, Corn TH (1988) Cholinergic "blockade" as a model for cholinergic depletion. A comparison of the memory deficits with those of 
Alzheimer-type dementia and the alcoholic Korsakoff syndrome. Brain 111:1079-1110.

Lamour Y, Dutar P, Jobert A (1984) Septo-hippocampal and other medial septum diagonal band neurons: electrophysiological and pharmacological properties. Brain Res 309:227-239.

Leranth C, Frotscher M (1989) Organization of the septal region in the rat brain: cholinergic-GABAergic interconnections and the termination of hippocampus-septal fibers. J Comp Neurol 289:304-314.

Levey AI, Edmunds SM, Heilman CJ, Desmond TJ, Frey KA (1994) Localization of muscarinic $\mathrm{M}_{3}$ receptor protein and $\mathrm{M}_{3}$ receptor binding in rat brain. Neuroscience 63:207-221.

Liu W, Kumar A, Alreja M (1998) Excitatory effects of muscarine on septohippocampal neurons: involvement of $\mathrm{M}_{3}$ receptors. Brain Res 805:220-233.

Markowska AL, Olton DS, Givens B (1995) Cholinergic manipulations in the medial septal area: age-related effects on working memory and hippocampal electrophysiology. J Neurosci 15:2063-2073.

Markram H, Segal M (1990) Electrophysiological characteristics of cholinergic and non-cholinergic neurons in the rat medial septum-diagonal band complex. Brain Res 513:171-174.

Miettinen R, Freund TF (1992) Convergence and segregation of septal and median raphe inputs onto different subsets of hippocampal inhibitory interneurons. Brain Res 594:263-272.

Moor E, de Boer P, Beldhuis HJ, Westerink BH (1994) A novel approach for studying septo-hippocampal cholinergic neurons in freely moving rats: a microdialysis study with dual-probe design. Brain Res 648:32-38.

Moor E, DeBoer P, Auth F, Westerink BH (1995) Characterisation of muscarinic autoreceptors in the septo-hippocampal system of the rat: a microdialysis study. Eur J Pharmacol 294:155-161.

Morris NP, Harris SJ, Henderson Z (1999) Parvalbumin-immunoreactive, fast-spiking neurons in the medial septum/diagonal band complex of the rat: intracellular recordings in vitro. Neuroscience 92:589-600.

Mufson EJ, Bothwell M, Kordower JH (1989) Loss of nerve growth factor receptor-containing neurons in Alzheimer's disease: a quantitative analysis across subregions of the basal forebrain. Exp Neurol 105:221-232.

Pavlides C, Greenstein YJ, Grudman M, Winson J (1988) Long-term potentiation in the dentate gyrus is induced preferentially on the positive phase of theta-rhythm. Brain Res 439:383-387.
Rouse ST, Levey AI (1996) Expression of $\mathrm{m}_{1}-\mathrm{m}_{4}$ muscarinic acetylcholine receptor immunoreactivity in septohippocampal neurons and other identified hippocampal afferents. J Comp Neurol 375:406-416.

Rupniak NM, Steventon MJ, Field MJ, Jennings CA, Iversen SD (1989) Comparison of the effects of four cholinomimetic agents on cognition in primates following disruption by scopolamine or by lists of objects. Psychopharmacology (Berl) 99:189-195.

Rusted JM, Warburton DM (1988) The effects of scopolamine on working memory in healthy young volunteers. Psychopharmacology (Berl) 96:145-152.

Segal M (1986) Properties of rat medial septal neurones recorded in vitro. J Physiol (Lond) 379:309-330.

Stewart M, Fox SE (1990) Do septal neurons pace the hippocampal theta rhythm? [See comments.] Trends Neurosci 13:163-168.

Toth K, Freund TF, Miles R (1997) Disinhibition of rat hippocampal pyramidal cells by GABAergic afferents from the septum. J Physiol (Lond) 500:463-474.

Vannucchi MG, Scali C, Kopf SR, Pepeu G, Casamenti F (1997) Selective muscarinic antagonists differentially affect in vivo acetylcholine release and memory performances of young and aged rats. Neuroscience 79:837-846.

Vilaro MT, Palacios JM, Mengod G (1990) Localization of m5 muscarinic receptor mRNA in rat brain examined by in situ hybridization histochemistry. Neurosci Lett 114:154-159.

Vilaro MT, Palacios JM, Mengod G (1994) Multiplicity of muscarinic autoreceptor subtypes? Comparison of the distribution of cholinergic cells and cells containing mRNA for five subtypes of muscarinic receptors in the rat brain. Mol Brain Res 21:30-46.

Whitehouse PJ, Price DL, Struble RG, Clark AW, Coyle JT, Delon MR (1982) Alzheimer's disease and senile dementia: loss of neurons in the basal forebrain. Science 215:1237-1239.

Woolf NJ, Butcher LL (1986) Cholinergic systems in the rat brain: III. Projections from the pontomesencephalic tegmentum to the thalamus, tectum, basal ganglia, and basal forebrain. Brain Res Bull 16:603-637.

Wu M, Shanabrough M, Leranth C, Alreja M (2000) Cholinergic excitation of septohippocampal GABA but not cholinergic neurons: implications for learning and memory. J Neurosci 20:3900-3908. 